\title{
Students experiences of peer-support during a Master's thesis process
}

\author{
Pirjo Kaakinen*1,2, Marjo Suhonen ${ }^{1,2}$, Sonja Lutovac ${ }^{3}$, Raimo Kaasila ${ }^{3}$ \\ ${ }^{1}$ Research Unit of Nursing Science and Health Management, University of Oulu, Oulu, Finland \\ ${ }^{2}$ Medical Research Group, Oulu, Finland \\ ${ }^{3}$ Faculty of Education, University of Oulu, Oulu, Finland
}

Received: November 2, 2016

Accepted: January 4, $2017 \quad$ Online Published: January 16, 2017

DOI: $10.5430 / \mathrm{cns} . v 5 \mathrm{n} 1 \mathrm{p} 22$

URL: http://dx.doi.org/10.5430/cns.v5n1p22

\begin{abstract}
Working as an expert in health care requires peer-support skills. The aim of the study is to describe students' $(\mathrm{n}=8)$ experiences of peer-support from other students during their Master's thesis process. This study was a qualitative and the data $(n=29)$ was collected from the students through a number of repeated open questions during one year. The data were analysed by a qualitative content analysis. The results show that students both received and gave individual and mental peer-support during their Master's thesis process. The results also show that students need to be active in peer-support group such as to share ideas, to discuss openly and to read peers thesis. The peer-support helped the students to formulate research plan and think more critically based on others students' feedback. Peer-support received in a group can help increase opportunities for learning working life skills for Master's thesis students, but further research is needed. More widely in health care, it is important to be aware of the existence of peer-support and discuss how it can be promoted.
\end{abstract}

Key Words: Peer-support, Group supervision, Master's thesis

\section{INTRODUCTION}

Learning during working life is one of the core components in health care. ${ }^{[1-3]}$ It requires academic, clinical and interpersonal skills. In health care, experts work in multiprofessional groups in which knowledge and skills can be shared. ${ }^{[4,5]}$ Because of this, individual learning skills alone are not sufficient for university students to fulfil true working life competence requirements. Working as an expert they additionally need peer-support skills. Learning with peersupport is commonly referred to as peer coaching and cooperative learning. ${ }^{[6]}$ Peer-support in the context of group supervision during studies enables students to practice their social skills and assist them in forming knowledge constructs. ${ }^{[7,8]}$
This promotes skills and competence in discussion at work as an expert. ${ }^{[7]}$ However, there is little evidence for health sciences university students learning in peer-support during a Master's thesis process, despite the widely recognized notions that the learning methods which support students' working together helps to build competence in working life.

In the context of group supervision, every member of a group is committed to common goals, processes and evaluation. This way the group is able to achieve together something that an individual in the group could not achieve alone. ${ }^{[9]}$ Students will engage in an active knowledge-structuring process within the group ${ }^{[10]}$ Peer-support is one component of social support that is connected to the students' learning. With peer-

\footnotetext{
*Correspondence: Pirjo Kaakinen; Email: pirjo.kaakinen@ oulu.fi ; Address:Research Unit of Nursing Science and Health Management, University of Oulu; Medical Research Group, Oulu, Finland.
} 
support in the context of group supervision in particular, students are all in the same situation and they need to co-operate to get their theses ready on time. ${ }^{[5,11]}$ Today one outcome of the students' learning process is the ability to engage in active learning as a member of a group. ${ }^{[12,13]}$ In a thesis group, interaction between peers is emphasized. ${ }^{[5,14]}$ During peer-support students receive support from each other. ${ }^{[7,13-15]}$ Peer-support gives students opportunities to develop their own thinking. This helps with knowledge structuring ${ }^{[16]}$ and with sharing key ideas and findings. ${ }^{[12,17]}$

Peer-support promotes students' learning ${ }^{[14,15]}$ and has been found beneficial for the learning process, both in practical and academic thesis work. ${ }^{[12,18,19]}$ Acting as a peer and providing support to other students has been shown to have a positive effect on problem solving skills ${ }^{[20]}$ and creates a supportive environment, which enables open group interaction. ${ }^{[7]}$ Students may help each other by providing constructive comments on thesis drafts, asking questions for clarification of study aims or for comprehension, and by resolving research-related problems together. ${ }^{[1,12,14,21-23]}$ As a result of this, they become more aware of their academic readers. Feedback also makes students aware of the steps of their research. ${ }^{[1,14,15]}$ Mutual motivational, mental and cognitive support also adds to the students' learning during their thesis process. ${ }^{[18,22]}$ Peer support further adds to students' self-confidence and critical thinking ${ }^{[5,24]}$ when students are able to share their fears of failure and their frustrations. ${ }^{[10,14,17,25]}$ Supportive feedback leads to motivation and self-confidence. ${ }^{[14,25]}$ Peer-support provides motivation, which makes the students' experiences of writing their Master's theses less lonely. ${ }^{[14]}$ This helps them to regulate their writing. ${ }^{[14]}$ In addition, mental peer-support reduces students' stress. ${ }^{[7,26,27]}$ According to Feingold et al., ${ }^{[1]}$ students were engaged and prepared carefully in peer-support group meetings, because they were accountable for the progress of the research for the group.

Previously, peer-support amongst students has been studied mostly from the viewpoint of educational science. ${ }^{[13,19,21,23,25]}$ There have also been studies from the viewpoint of nursing science ${ }^{[1,18,26,27]}$ and dental education, ${ }^{[4]}$ psychology ${ }^{[20]}$ and physiotherapy. ${ }^{[6]}$ There are also some studies on academic doctoral dissertation writing processes in group or pair contexts. ${ }^{[14,17]}$ Most studies have focused on university students' learning outcomes and their experiences related to peer-support, although it is claimed that there are only a few studies of university students' experiences of peer group working. ${ }^{[24,28]}$ Other previous studies have focused on interaction between students during group supervision, ${ }^{[7]}$ and nursing students' peer-support. ${ }^{[5,12]}$
The participants in this study differ from participants in previous studies focusing on peer support in the field of health care. Most participants in the present study are nursing students, ${ }^{[5,12,24]}$ and only some studies focus on Bachelor students at university. ${ }^{[7]}$ The participants are Master students in health sciences, so they are studying at the highest level in nursing and health sciences study system before doctoral degree studies in Finland. Additionally, the differences in education of nursing and health sciences vary between the different countries, which creates challenges in comparing the group supervision of students' thesis among the countries. In Finland, registered nurses are educated in University of Applied Science and its focus is clinical practice. While the students are studying in the University of Health Science, they are already registered nurses and studies included in the scientific and research work. Those nurses are rarely employed in clinical practice. In the health care field there are different requirements for Master students in working life, so they should be able to practice scientific working methods to developing and working life skills. However, the same issue has not been explored in the context of the Master's thesis process. There is a lack of knowledge of the peer support of Master's thesis process in Health Science, and of how that will impose added working life requirements.

The aim of the study is to describe the students' $(n=8)$ experiences of peer-support from other students during their Master's thesis process. The research question is: What kinds of experiences do students have of peer-support during their Master's thesis process?

\section{IMPLEMENTATION OF GROUP SUPERVI- SION IN THE MASTER'S THESIS PROCESS}

Master theses at Oulu University are implemented under group supervision, where all three health management science teachers have their supervision group. From the perspective of collaborative learning, the each teacher's responsibility is to create such a learning situation where members of the group need each other to construct knowledge and they are able to achieve their learning goals together. In this sort of learning each student's individual learning goals are linked to the group's common goals. ${ }^{[18,22]}$ In the supervision of the Master theses, the teacher role is formed small groups consisting of three to five students and these groups meet each other five time during master theses process. The teacher was with two supervision groups, and three supervision groups were comprised of only students. Once the groups had been formed, each student group selected a group leader, whose responsibility was to agree with the teacher on three group supervision appointments a year. 
The teacher's role was to read the students' thesis drafts and questions before the group supervision appointments and to act as the head of the peer-support group. The teacher gave oral and written feedback in the group appointments. Each group supervision appointment was implemented in a slightly different manner. Sometimes the students presented the stage their thesis had reached, and then there was some common discussion about the students' situations where solutions to their challenges were reflected upon. In addition, each student brought his or her own special issues during the discussion in the group appointments.

Three to five days prior to a supervision appointment the students sent their own thesis drafts and questions to the teacher and peer-support group. Students familiarized themselves with each other's thesis texts before the meeting, and they actively participated the discussion and gave feedback to each other. Those supervision appointments where the teacher was not present worked the same way. In the times between the group supervision appointments the students worked independently, writing their theses.

\section{RESEARCH METHODOLOGY}

\subsection{Data collection}

Before data collection, voluntary consent of the informants was obtained and the aims of the study were explained to the participants. Based on Finnish law, we did not need the approval of an Ethical Committee to carry out the study. The results were reported so that individual informants could not be identified. ${ }^{[29]}$

The participants were health management science students, whose studies were at the Master's thesis stage. Convenience sampling was used in the study. There were three Master's thesis groups in health management science in 2012. One teacher, who was also the writer of this research, invited Master's thesis students $(n=8)$ to participate in the study. Those students who agreed to participate in the study gave their informed consent to this.

Group supervision appointments took place three times in the semester and the students had two appointments without a teacher and their duty in these meetings was to discuss the progression of their theses. For each supervision appointment, the progress and phase of the theses affected the theme of the supervision appointment. After each appointment the teacher distributed the questionnaire used as the basis for this research to the group. The questionnaire was used to get richer and deeper information and the group were given opportunity to answer the questionnaire without teacher presence. The questions were developed based on literature and tested with one students group, which were not included this study. On the two first supervision appointments the data was formed from the answers to the following open question: "Consider and evaluate your learning during the Master's thesis." This question was further specified with the following questions: "Please describe some examples of peer-support from others students related to your learning. Please describe what your learning has been like. What kinds of learning experiences you have had related to peer-support?" Because of the saturation of the data, ${ }^{[30]}$ the study questions were changed for the last three supervision appointments to obtain richer data. After the changes were made the question now read, "Describe the support that you have had from other students." After the changes, the students answered for the question more deeply about peer-support.

The students answered the questions at the end of supervision appointments. There were students who did not participate in the supervision appointment every time, so supervision appointments produced 29 answers in total. The lengths of answers varied from seven lines to one page.

\subsection{Data analysis}

The study follows a qualitative research approach. ${ }^{[31]}$ The data were analysed using qualitative content analysis. ${ }^{[30]}$ The aim was to form a well-structured overall picture of the students' experiences related to the peer-support from other students during in their Master's thesis process. ${ }^{[31]}$ Firstly, the answers to the open questions were read many times and coded by two researchers (PK, MS). The coded expressions were divided into groups with the same meaning, [31] Each group described students' experience of peer-support. Secondly, the expressions were organized with the same meaning subcategories and named according to their content. Third, the subcategories were combined into head-categories and named based on their content. In the each phase the researchers made independently analysis and discussed the results of analysis. The head-categories were named as follows: Support based on social pressure, Strong mental support, Open interaction and challenges in giving feedback. The categories were combined under one main category: Individual and mental peer-support supervision during the Master's thesis process (see Table 1).

\section{INDIVIDUAL AND MENTAL PEER-SUPPORT DURING THE MASTER'S THESIS PROCESS}

The students' experiences of peer-support from other students during the Master's thesis process were divided into three sub-categories: Support based on social pressure, Strong mental support and Open interaction and feedback. 
Table 1. Data analysis process and the findings

\begin{tabular}{|c|c|c|}
\hline Sub-categories & Head categories & Main category \\
\hline $\begin{array}{l}\text { - Knowing that group exists helped } \\
\text { peer-support } \\
\text { - The group members made positive } \\
\text { pressure to own work }\end{array}$ & $\begin{array}{l}\text { - Support based on positive social } \\
\text { pressure }\end{array}$ & \\
\hline $\begin{array}{l}\text { - Good atmosphere in the group } \\
\text { - All the group members had the same } \\
\text { kind of challenges during the Master's } \\
\text { thesis process } \\
\text { - Others were motivated } \\
\text { - Feeling that the Master's thesis process } \\
\text { will succeed }\end{array}$ & - Strong mental support between peers & $\begin{array}{l}\text { - Individual and mental peer-support } \\
\text { during the Master's thesis process }\end{array}$ \\
\hline $\begin{array}{l}\text { - Bringing out different kind of views } \\
\text { between peers } \\
\text { - Group as a forum for re-outlining one's } \\
\text { own thesis } \\
\text { - Shared discussion }\end{array}$ & $\begin{array}{l}\text { - Open interaction and challenges in } \\
\text { giving feedback in terms of } \\
\text { peer-support }\end{array}$ & \\
\hline
\end{tabular}

\subsection{Support based on positive social pressure}

According to the students, the existence of the peer-support group led to positive social pressure and it motivated the group members. Students noticed that some students were further along with their theses than others and this led them to do more work on their own theses. The group scheduled the thesis work as well; when the supervision appointment got closer the students felt they needed to produce more text to bring to the meeting.

"When the deadline comes near I have to bring out something. ... I feel social pressure.” (1)

The existence of peer-support was set felt to be very important. Students encouraged each other by discussing the thesis process and this led to social pressure. Within the group, students who were working as nurses were able to discuss their studies together and be in touch with their own university. In this way writing the Master's thesis was not so lonely.

"The existence of the group was enormously important for me because then I was able to keep in touch with the university. When I am working as a nurse the studies tend to get forgotten." (12)

"At this phase of the Master's thesis it is important to meet other students in the same situation. We have the chance to discuss things with others." (19)

\subsection{Strong mental support between peers}

During the peer-support there was a strong degree of mental support. This was evident in positive interactions, which created a good atmosphere and open discussion in the group.
"The group work has proceeded in a constructive and pleasant atmosphere." (4)

"Learning experiences have been positive in an encouraging atmosphere." (5)

The mental support expressed by the group studied also included the feeling of being able to share negative feelings such as frustration, stress and feelings of inadequacy with their theses. Mental support included discussions about own uncertainty related to the Master's thesis and the opportunity to encourage one another on. Furthermore, mental support also arose due to feelings of success after group supervision. It was important for the students to feel that other members of the peer-support group were in same situation and that they were not alone with their theses. In addition, peer-support was effective for problem solving. Although students had different kinds of subjects and research methods in their theses, all students had topics to discuss in the group. Students solved problem together as how to collect data or to construct the content of the thesis. According to the students, mental support was the biggest support and supervision received and given amongst peers. However, they also received and gave useful advice on practical issues related to their theses, such as how to format a table of contents, add headings and references etc.

"Peer-support is important because I notice that I am not alone with my problems." (13)

"The biggest guidance and support was mental. It is relieving to notice that we all think about same kinds of problems/challenges, although our research questions, designs and methods are different." (21) 
The students supported each other. They had promised to be in contact, for example by e-mail. It felt good that others read their research reports. Each group gave support to its members and students experienced being able to spread their own enthusiasm to others.

"Although I am much behind compared to other students I have had support via e-mail and by phone as well. The support has been both concrete and mental. I have had advice on what section should be made more focused or wider." (25)

The students benefitted the peer support. The peer-support group have an essential role in managing the students' Master's thesis process because they described that they gained reassurance. Peer students made them believe themselves that they were able to get through the Master's thesis process.

"After the first supervision meeting I felt that I would be able maybe to manage the work because I received support and guidance from other students." (3)

"I have had support and guidance very well. I can have encouragement from others and encourage others - enthusiasm can spread!” (13)

\subsection{Open interaction and challenges in giving feedback in terms of peer-support}

Interaction in the peer-support group was very open and it supported the Master's thesis process. Peer-support gave the students new perspectives and ideas for their own theses; students especially gained new ideas from other students' research plans and reports. Students noted the peer-support helped them to design and write their own research plans and reports better because discussion amongst group members was possible. Discussion made the students think more critically about their theses and promoted their writing. The discussions in the peer support meetings were based on reading other students writing. This made it possible to ask questions and seek answers to those questions common to the group. Discussions about different solutions to individual student's challenges were seen as especially important. Questions posed by other students helped the learning while students had to rationalize their own choices to others.

"During group meetings we have been open discussions that support our work.” (18)

"Discussion helped to outline the work in a new way and made me consider issues and made me think more and encouraged me to work." (9)

"Learning is promoted by questions from other students. Those questions make me rationalize my choices to others."
Students saw also challenges in giving feedback to their peers. Although the peer-support group was encouraging, some of students did not have adequate self-confidence. They realized during the supervision, that they did not have sufficient knowledge about the research work so they did not ask the other students questions. These students felt uncertain about their ability to give peer supervision and they were concerned about giving the wrong advice. They did not have enough courage to make final decisions during peer-support group meetings.

"At the beginning maybe I did not have the talent to ask the right questions or to ask enough questions." (18)

"We have been discussing some elements but because our theses are unfinished our work is hard to evaluate by other students.” (22)

\section{Discussion}

This study described students' experiences about individual and mental peer-support during Master's thesis process as a whole. Basic premise of peer-support was student's activity and open-minded participation in a group. This study also described the content and aspects of peer-support related to students learning during Master's thesis supervision. Previous studies have identified the need of peer-support and its existence during thesis process amongst health sciences university students, ${ }^{[7]}$ but they have not described the content of peer-support. In particular, peer-support in the context of Master's thesis supervision has not been studied before.

The results show that students both received and gave individual and mental peer-support during their Master's thesis process. The results also show that students need to be active and take responsibility in giving and receiving peer-support in the group. Good interpersonal and interaction skills help students to succeed in this during the Master's thesis process. Peer-support received in a group can help maximize opportunities for learning working life skills for Master's thesis students, but the further research is needed.

The study shows that peer support consisted of positive social pressure, strong mental support and open interaction. All these are related to one another and they make together a whole where parts can be discussed related to the whole. Mental support was an essential part of peer-support. Mental support reduced the students' stress and anxiety related to their Master theses process. Previous studies show that feedback from peers decreases anxiety, ${ }^{[24]}$ but feedback has not been studied to this degree of detail in terms of peer-support before. When students had mental support from each other that help them to get their Master's thesis finished on time. This was promoted by pleasant and permissive atmosphere 
that was felt encouraging. The permissive atmosphere made it easier for students to share mental frustrations and solved research problems together, and they also helped each other through the Master's thesis process. This in turn helped them towards positive learning outcomes. Sharing frustration and problem solving has also been seen in previous studies, ${ }^{[14,17]}$ but helping each other in the work in terms of peer-support so that it could be accomplished was emphasized in our study. Mental support was promoted by open interaction between peers. In particular, different views that were openly shared in the group were key to successful peer-support. According to Baker et al. ${ }^{[12]}$ giving feedback promoted progress on the theses, because students received encouragement from many peers. These abilities showing in our study are also strongly related to working life skills more widely in health care work.

Well working interaction was fundamental important for successful peer-support. This might be one reason why mental support does not necessary materialize in every peer-support group: The students' dissimilarity in interpersonal and interaction skills is an issue. Not everybody has the necessary interaction skills to receive and give peer-support in a group or the courage to participate in the discussions in terms of peer-support. The ability to give and receive feedback and social support is one skill in working life as well, which can be practiced in a peer-support group. The importance of a well-working atmosphere has been identified in previous studies, ${ }^{[12,24]}$ but reasons for well-working peer-support in a group have not been identified in previous studies related to nursing students of health science students. It is important to take this into account in the Health Science education, how to promote students to use their expertise and practice their argumentations skills. Previous studies have found that for progress to be made in writing a Bachelor's thesis, there is a need for peer support and peer supervision. The role of the teacher is also important. ${ }^{[7,17]}$ In a thesis group, it is important for the students to understand their own role as a member of a peer-support group. Otherwise, if members do not carry out their responsibilities and commit to give peer-support, or do not have the skills for it, this might pose challenges for peer-support. These skills are related to working life skills, so it is important that both nurses and managers identify their own interpersonal and interaction skills, and give their own contribution for the benefit of the group atmosphere. It is also important to be aware of the existence of peer-support in work groups and of how it can be nurtured.
Peer-support was suitable for adult students who typically already had nursing education and for this reason they also already had some experience of work with a lot of responsibility. Furthermore, previous studies emphasize students' commitment to group work. ${ }^{[9]}$ This study emphasizes students' responsibilities in giving and receiving peer-support, which confirm the findings of previous studies. ${ }^{[7]}$

In this study trustworthiness is ensured by using Lincoln and Cuba's ${ }^{[32]}$ criteria of credibility, dependability, transferability and confirmability. Credibility is further supported by the fact that two researchers analysed the data on their own and after that drew the conclusions together. Credibility is also supported because the data was collected in an actual environment and there are quotes presented from the original data. Although study population was small, the reader can evaluate how the results may be transferred to similar kinds of group supervision situations. The readers can evaluate the transferability of results case specifically in similar kinds of situations, although transferability of the results is not aimed for in this study. The trustworthiness of the study could have been increased by answers to the open questions from a larger number of groups or by interviewing the students.

\section{Conclusions}

The study identified the content of peer-support in the context of health science Master's thesis group supervision. The study showed that mental support was the most important part of peer-support. Peer-support supervision added to students working life skills. Peer-support in the context of group supervision was a well-working method for Master's thesis supervision, and therefore peer-support should be integrate into masters' level curriculum to enhance student learning. It supported students in completing their Master theses within the given time and helped them to reflect upon emotions during the process. More generally in health care, it is important to be aware of the existence of peer-support, and to discuss how it can be nurtured. In further studies it is important to explore university students more deeply from the viewpoint of what kind of skills and requirements there are for successful peer-support amongst both students and teachers. Mental support amongst students is important to study more profoundly with for example for open interview.

\section{CONFLICTS OF INTEREST Disclosure}

The authors declare that they have no conflict of interest. 


\section{REFERENCES}

[1] Feingold CE, Cobb MD, Givens RH, et al. Student perceptions of team learning in nursing education. Journal of Nursing Education. 2008; 47(5): 214-222. PMid: 18522153. https ://doi .org/10.3 928/01484834-20080501-03

[2] Järvenoja H. Socially shared regulation of motivation and emotions in collaborative learning. Academic dissertation. Acta Univ. Oul. E 110. Faculty of Education, University of Oulu. 2010.

[3] O'Brien A, Giles M, Dempsey S, et al. Evaluating the preceptor role for pre-registration nursing and midwifery student clinical education. Nurse Education Today. 2014; 34(1): 19-24. PMid: 23623277. https ://doi.org/10.1016/j.nedt.2013.03.015

[4] Divaris K, Barlow PJ, Chendea SA, et al. The academic environment: the students' perspective. European Journal of Dental Education Official Journal of the Association for Dental Education in Europe. 2008; 12(Supplement s1): 120-130. PMid: 18289275. https://doi.org/10.1111/j.1600-0579.2007.00494.x

[5] Yang K, Woomer G, Matthews J. Collaborative learning among undergraduate students in community health nursing. Nurse Education in Practice. 2012; 12(2): 72-76. PMid: 21820963. https: //doi.org/10.1016/j.nepr.2011.07.005

[6] Ladyshewsky RK. A quasi-experimental study of the differences in performance and clinical reasoning using individual learning versus reciprocal peer coaching. Physiotherapy Theory and Practice. 2002 18(1): 17-31. https://doi.org/10.1080/0959398027535706 66

[7] Kangasniemi M, Ahonen SM, Liikanen E, et al. Health science students' conceptions of group supervision. Nurse Education Today. 2011; 31(2): 179-183. PMid: 20598404. https ://doi .org/10.1 016/j.nedt. 2010.05 .015

[8] Lidon I, Rebollar R, Moller C. A Collaborative learning environment for management education based on experimental learning. Innovation in Education and Teaching International. 2011; 4(3): 301-312. https://doi.org/10.1080/14703297.2011.593706

[9] Judd T, Kennedy G, Cropper S. Using wikis for collaborative learning: Assessing collaboration through contribution. Australasian Journal of Educational Technology. 2010; 26(3): 341-354. https : //doi.org/10.14742/ajet. 1079

[10] Scardamalia M, Bereiter C. Knowledge building: Theory, pedagogy and technology. In: Sawyer, K. (ed.), Cambridge Handbook of the Learning Sciences. New York: Cambridge University Press; 2006 97-118 p.

[11] Dillenbourg P. What do you mean by 'collaborative learning'? In: Dillenbourg P. (Eds.), Collaborative-learning: Cognitive and Computational Approaches Elsevier, Oxford; 1999. 1-19 p.

[12] Baker MJ, Cluett E, Ireland L, et al. Supervising undergraduate research: A Collective approach utilizing group work and peer support. Nurse Education Today. 2014; 34(4): 637-642. PMid: 23755837. https://doi.org/10.1016/j.nedt.2013.05.006

[13] Gielen M, De Wever B. Structuring peer assessment: Comparing the impact of the degree of structure on peer feedback content. Computers in Human Behavior. 2015; 52: 315-325. https: //doi.org/10.1016/j.chb.2015.06.019

[14] Li LY, Vandermensbrugghe J. Supporting the thesis writing process of international research students through an ongoing writing group. Innovations in Education and Teaching International. 2011; 48(2): 195-205. https://doi.org/10.1080/14703297.2011.564014

[15] Ertmer P, Richardson J, Belland B, et al. Using peer feedback to enhance the quality of student online postings: an exploratory study. Journal of Computer-Mediated Communication. 2007; 12(2). https://doi.org/10.1111/j.1083-6101.2007.00331.x
[16] Johnson D, Johnson R. An educational Psychology success story: Social interdependence theory and cooperative learning. Educational Researcher. 2009; 38(5): 365-379. https://doi.org/10.3102/ $0013189 \times 09339057$

[17] Webb AK, Wangmo T, Ewen $\mathrm{H}$, et al. Peer and faculty mentoring for students pursuing a $\mathrm{PhD}$ in gerontology. Educational Gerontology. 2009; 35(12): 1089-1106. https://doi.org/10.1080/036012 70902917869

[18] Christiansen A, Bell A. Peer learning partnerships: exploring the experience of pre-registration nursing students. Journal of Clinical Nursing. 2010; 19(5-6): 803-10. PMid: 20500324. https: //doi.org/10.1111/j.1365-2702.2009.02981.x

[19] Marshall J, Lawrence E, Williams J. Mentoring as service-learning: the relationship between perceived peer support and outcomes for college women mentors. Studies in Educational Evaluation. 2015; 47: 38-46. https ://doi.org/10.1016/j.stueduc. 2015.07.001

[20] Karantzas G, Avery M, Macfarlane S, et al. Enhancing critical analysis and problem-solving skills in undergraduate psychology: An evaluation of a collaborative learning and problem-based learning approach. Australian Journal of Psychology. 2013; 65(1): 38-45. https://doi.org/10.1111/ajpy.12009

[21] Colvin JW. Peer tutoring and social dynamics in higher education. Mentoring and Tutoring. 2007; 15(2): 165-81. https ://doi .org/ $10.1080 / 13611260601086345$

[22] Repo S. A sense of community as a resource for developing university teaching and learning. Institute of Behavioural Sciences Educational Sciences Research Report 228, 2010, University of Helsinki. 2010.

[23] Reynolds JA, Thompson RJ. Want to improve undergraduate thesis writing? Engage students and their faculty readers in scientific peer review. CBE - Life Science Education. 2011; 10(2): 209-215. PMid: 21633069. https : //doi.org/10.1187/cbe.10-10-0127

[24] Wiggs C. Collaborative testing: Assessing teamwork and critical thinking behaviors in baccalaureate nursing students. Nurse Education Today. 2011; 31(3): 279-282. PMid: 21084136. https: //doi.org/10.1016/j.nedt.2010.10.027

[25] Dysthe O, Samara A, Westrheim K. Multivoiced supervision of master's students: a case study of alternative supervision practices in higher education. Studies in Higher Education. 2006; 31(3): 299-318. https ://doi.org/10.1080/03075070600680562

[26] Hamrin V, Weycer A, Pachle M, et al. Evaluation of peer-led support groups for graduate nursing students. Research Brief. 2007; 45(1): 39-43.

[27] Thomka LA. Mentoring and its impact on intellectual capital: through the eyes of the mentee. Nursing Administration Quarterly. 2007; 31(1): 22-26. PMid: 17198115. https://doi.org/10.1097/00 006216-200701000-00008

[28] Ruys I, Van Keer H, Aelteman A. Collaborative learning in preservice teacher education: an exploratory study on related conceptions, self-efficacy and implementation. Educational studies. 2010; 36(5): 537-553. https://doi.org/10.1080/03055691003729 021

[29] Denzin NK, Lincoln YS. The SAGE Handbook of Qualitative Research. 4th ed. California: Sage Publications; 2011.

[30] Elo S, Kyngäs H. The qualitative content analysis process. Journal of Advanced Nursing. 2008; 62(1): 107-115. PMid: 18352969. https://doi.org/10.1111/j.1365-2648.2007.04569.x

[31] Polit DF, Beck CT. Nursing research. Generating and assessing evidence for nursing practice. 9th ed. Lippincott Williams \& Wilkins, Philadelphia. 2011.

[32] Lincoln YS, Cuba EG. Naturalistic inquiry. Beverly Hills, California: Sage Publications; 1985. 